\title{
Correspondence
}

\section{Nasotracheal intubation in patients with an unanticipated difficult airway - I}

To the Editor:

We read, with interest, the recent case report written by Drs. Uria et al. ${ }^{1}$, and we agree with their assessment that it is important to perform a preliminary laryngoscopy prior to inserting a nasal tube. However, their recommendation to insert a bougie through the RAE® nasal tube, with its distal acute curve, can result in inappropriate bending of the distal portion which is unfavourable to insertion of the bougie into the laryngeal aperture. Also, the gritty feel in contact with the tracheal rings ${ }^{2}$ has the potential to interfere with the operator's judgment of correct tracheal placement of the bougie, particularly when a $7.5-\mathrm{mm}$ oral tube is inserted between the vocal cords. Moreover, we have found that digital displacement of the oral tube, posteriorly and rostrally, in patients with an unanticipated difficult airway, cannot always bring the vocal cords into view. Therefore, we consider the airway management plan outlined by Uria et al. to be suitable for those patients where facemask ventilation can be easily achieved or for situations where fibreoptic equipment is unavailable.

When the laryngeal views obtained by preliminary laryngoscopy are Cormack-Lehane grades 3 or 4, we prefer a modified Piepho's algorithm to perform nasal intubation. ${ }^{3}$ If facemask ventilation is not difficult, we use fibreoptic nasal intubation as our primary option. To avoid the potential danger of causing bleeding by insertion of a nasal tube, we usually select the nasal tubes made from soft flexible materials such as the Portex ${ }^{\circledR}$ Ivory PVC cuffed tube (Sims Portex Ltd., Kent, UK), because this tube can be passed through the nasal passage with a minimum of mucosal damage. ${ }^{4}$ We do not encourage use of the RAE ${ }^{\circledR}$ nasal tube during fibreoptic intubation, because its preformed curve can interfere with fibrescopy, and there may be difficulty in advancing the tube over the fibreoptic bronchoscope (FOB) into the trachea.

If facemask ventilation is difficult, an intubating laryngeal mask airway is inserted to maintain a patent airway and to provide a channel for orotracheal intubation using the FOB or the lightwand. To ensure con- venience for subsequent tube exchange, we advocate inserting an oral endotracheal tube with an internal diameter $1-1.5 \mathrm{~mm}$ smaller than the intended endotracheal tube. After the nasal tube, obturated with an inflated Foley catheter, is guided through the nostril into the hypopharynx, according to the methods described by Russell, ${ }^{5}$ the FOB is inserted via the nasal tube into the trachea alongside the oral tube. Next, the oral to nasal tube exchange is completed. In our experience, due to the ability to maintain adequate lung ventilation while minimizing the risk of epistaxis, this modified Piepho's algorithm can provide additional safety during nasotracheal intubation.

Fu S. Xue MD

Xu. Liao MD

Ya C. Xu MD

Plastic Surgery Hospital, Chinese Academy of Medical Sciences and Peking Union Medical College, Beijing, P. R. of China.

E-mail: fruitxue@yahoo.com.cn

Competing interests: None declared.

Accepted for publication June 20, 2008.

\section{References}

1 Uria M, Kost K, Schricker T, Backman SB. Case report: Nasotracheal intubation - look before leaping to assess the laryngeal view. Can J Anesth 2008; 55: 302-5.

2 McCarroll SM, Lamont BJ, Buckland MR, Yates AP. The gum-elastic bougie: old but still useful. Anesthesiology 1988; 68: 643-4.

3 Piepho T, Thierbach A, Werner C. Nasotracheal intubation: look before you leap. Br J Anaesth 2005; 94: 859-60.

4 George L. Epistaxis and nasal tubes. Anaesth Intensive Care 2003; 31: 122.

5 Russell W. Atraumatic nasal intubation. Anaesthesia 1996; 51: 1084.

\section{Nasotracheal intubation in patients with an unanticipated difficult airway - II}

To the Editor:

I read, with interest, the case report: Nasotracheal 
intubation - look before leaping to assess the laryngeal view, ${ }^{1}$ describing a technique for performing nasotracheal intubation in patients with difficult intubation on direct laryngoscopy. The authors state in the article that orotracheal intubation can be achieved using a variety of techniques, including videolaryngoscopy. An important addition to their article, also very useful in performing nasotracheal intubations, would be the GlideScope (Verathon, Bothell, WA, USA). Since the authors do not include the GlideScope in the algorithm presented in the article, I recommend they revise their list to create an up-to-date schematic. If the vocal cords are well visualized with the GlideScope, it would be logical to proceed with the nasotracheal intubation. In a prior study utilizing the GlideScope, nasotracheal intubation was successful in $17 / 20$ intubations and successful in $8 / 11$ with modified Cormack-Lehane scale $3-4 .^{2}$ In another study, the GlideScope was successful in facilitating nasotracheal intubation in 10/10 patients; all were accomplished without the assistance of Magill forceps. ${ }^{3}$ If available for use, the interesting and useful technique described by Uria et al. ${ }^{1}$ could also be facilitated with the use of the GlideScope.

Steven M. Neustein MD

Mount Sinai Medical Center, New York, USA

E-mail: steve.neustein@mountsinai.org

Accepted for publication June 20, 2008.

\section{References}

1 Uria M, Kost K, Schricker T, Backman S. Case report: Nasotracheal intubation-look before leaping to assess the laryngeal view. Can J Anesth 2008; 55: 302-5.

2 Hirabayashi $\Upsilon$. GlideScope videolaryngoscope facilitates nasotracheal intubation Can J Anesth 2006; 53 : 1163-4.

3 Lai HY, Chen IH, Chen A, Hwang FY, Lee $\Upsilon$. The use of the GlideScope for tracheal intubation in patients with ankylosing spondylitis. Br J Anaesth 2006; 97 : 419-22.

\section{Reply:}

We thank Drs. Xue et al. and Dr. Neustein for their interest and comments regarding our recent article. ${ }^{1}$ We would like to begin by reiterating that our case report advocates the importance of formulating an airway management plan for nasal intubation. Since epistaxis can interfere with visualization of the oropharynx and so impede intubation, we stress the importance of direct laryngoscopy prior to insertion of an endotracheal tube through the nose. If confronted by a potentially difficult airway, the airway can initially be secured via the oral route, and afterwards, the potential for oral to nasal tracheal tube exchange can be considered in a controlled manner. Our article describes an effective and simple conversion strategy for oral to nasal tube exchange that can be modified to accommodate a variety of airway scenarios.

In response to Drs. Xue and colleagues, we did not find that the nasal RAE® Mallinckrodt tube interfered, in any way, with insertion of the Eschmann bougie through the tube and into the glottic opening. We acknowledge that a variety of endotracheal tubes are appropriate for nasal intubation. We agree that nasal $R A E \Theta$ tubes are not ideally mated to the fibreoptic bronchoscope technique, and this was not advocated. The technique of digital displacement of the oral tube to bring the vocal cords into view has not been extensively studied, ${ }^{3}$ and we acknowledge Xue et al.'s anecdotal experience with its limitations. The management plan which we suggest does not depend on the ease of facemask ventilation or the availability of fibreoptic equipment, as emphasized in the discussion of our manuscript. On the contrary, we stressed the importance of maintaining ventilation of the lungs to permit adequate oxygenation, which can be achieved with a variety of techniques (e.g., supraglottic airway devices) in addition to endotracheal intubation. We acknowledged previous reports describing the use of a bronchoscope to guide an endotracheal tube through the nasal passage and into the trachea prior to, or following, removal of a previously inserted orotracheal tube. ${ }^{4}$

$D r$. Neustein suggests that, if the vocal cords are well visualized with the Glidescope $®$, one can proceed directly with nasotracheal intubation. However, in the event of epistaxis, the Glidescope's ${ }^{\circledR}$ usefulness to facilitate endotracheal intubation, through either orifice, may be compromised. We agree, however, that the Glidescope $\AA$ is a useful device and should be considered as one of several choices to achieve oral intubation, when this is not possible using conventional laryngoscopy, as highlighted in the Figure and the text of our report. A further consideration, which was not raised in our paper, is the use of videolaryngoscopy, following oral intubation, to guide a bougie (or tube exchanger) into the trachea via the nose so that it may be used as a guide for subsequent nasotracheal intubation.

As a final comment, we emphasize that the concern of this manuscript is not to provide an airway management protocol for every conceivable combination of difficulties with ventilation and/or intubation. Rather, this manuscript emphasizes an approach to nasotracheal intubation that complements, rather than competes with, the 


\section{sophisticated airway management algorithms already in} place.

Steven B. Backman MDCM PhD FRCPC

Thomas Schricker MD PhD

Royal Victoria Hospital, McGill University Health Center, Montreal, Canada

E-mail: steven.backman@muhc.mcgill.ca

\section{References}

1 Maria M, Kost K, Schricker T, Backman SB. Case report: Nasotracheal intubation - look before leaping to assess the laryngeal view. Can J Anesth 2008; 55: 302-5.

2 Piepho T, Thierbach A, Werner C. Nasotracheal intubation: look before you leap. Br J Anaesth 2005; 94 : 859-60.

3 Ford $R W$. Confirming tracheal intubation - a simple manoeuvre. Can Anaesth Soc J 1983; 30: 191-3.

4 Smith JE, Fenner SG. Conversion of orotracheal to nasotracheal intubation with the aid of the fibreoptic laryngoscope. Anaesthesia 1993; 48: 1016.

\section{Tracheal intubation using the Bonfils intubation fibrescope in patients with a difficult airway}

To the Editor:

We read, with interest, the report by Byhahn et al. ${ }^{1}$ in which they compare using a Bonfils intubation fibrescope (BIF) to using direct laryngoscopy, to facilitate tracheal intubation in patients with a simulated difficult airway. In our view, selecting a laryngoscopic intubation under general anesthesia as a control group tends to obscure the purpose and clinical significance of the study. If the authors' intent was to determine whether the BIF was a more effective intubating device for patients with a known difficult airway, compared to other instruments, perhaps a study design involving awake intubation should have been considered. According to the American Society of Anesthesiologists' difficult airway algorithm ${ }^{2}$ awake intubation is the safest option for patients with a known difficult airway. Furthermore, a fibreoptic bronchoscope (FOB) may be a more suitable control device, since awake fibreoptic intubation is often regarded as a cornerstone in the management of a known difficult airway. If the study had been designed to assess the usefulness of the Bonfils for managing an unanticipated difficult airway, perhaps the lightwand should have been considered as

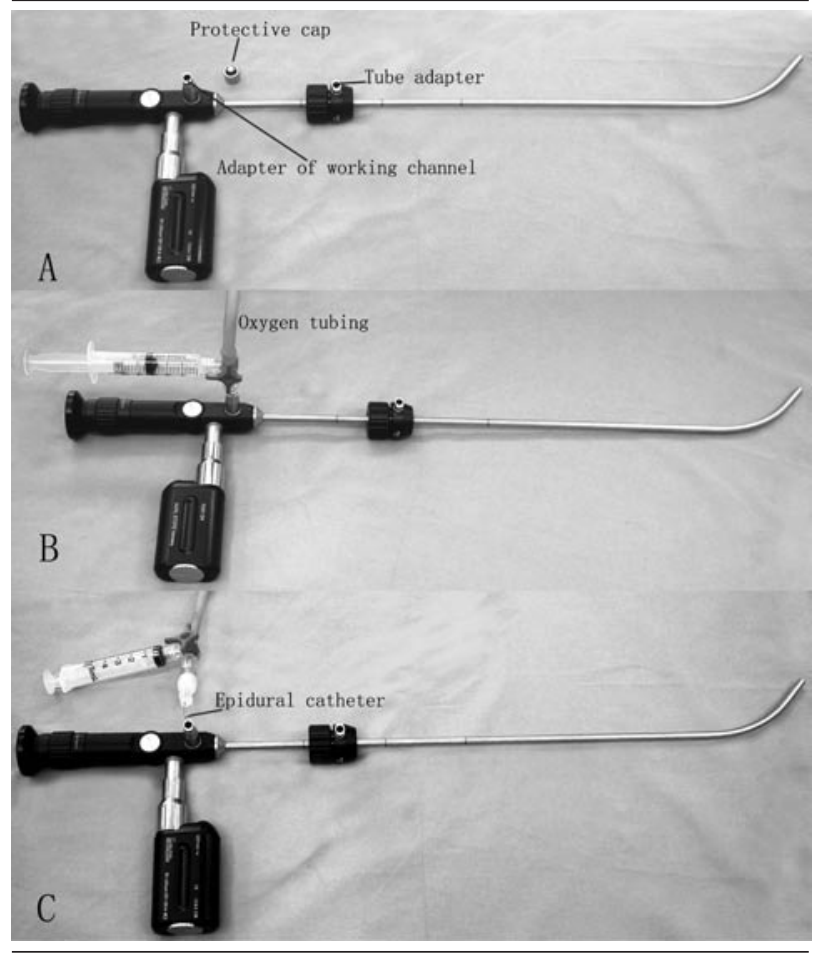

FIGURE The Bonfils retromolar intubation fibrescope ${ }^{\mathrm{TM}}$ with a 1.2-mm working channel (Bonfils 10031 B, Karl Storz Endoscopy, Tuttlingen, Germany) (Panel A). To spray lidocaine in the airway using the "spray as you go" technique, an oxygen tubing and a Luer-locked syringe prefilled with lidocaine are connected to the working channel of the Bonfils (Panel B) or an epidural catheter is placed in the working channel of the Bonfils (Panel C) by a triple stopcock.

a control device, rather than a laryngoscope for direct laryngoscopy. The lightwand intubating technique has been recommended as the first-line option in patients whose lungs can be ventilated, but who have a failed laryngoscopic intubation. ${ }^{3}$

It appears that the study design used a BIF without a working channel. We draw attention to the existence of a commercially available, adult version BIF with a 1.2mm working channel (Figure - Panel A). We often use this Bonfils with a working channel for patients with a known difficult airway, to perform the awake intubation by the "spray as you go" technique (Figure - Panels B and $\mathrm{C}$ ), which is similar to the technique using a FOB. Compared to administering lidocaine in the airway via the tube adapter of the BIF, ${ }^{4}$ spraying lidocaine via a thin working channel is more effective for topical airway anesthesia, due to a more accurate direction of lidocaine stream to the targeted sites and less drug wastage. Compared to an intubation technique using a combination of the Macintosh laryngoscope and the Bonfils, as reported in this study, we prefer to use a midline 